\title{
Correction to: The effects of the Summer All Out Foot Patrol Initiative in New York City: a difference-in-differences approach
}

\author{
Thomas J. Bilach ${ }^{1}$. Sean Patrick Roche ${ }^{2} \cdot$ Gregory J. Wawro ${ }^{3}$
}

Published online: 3 August 2021

(c) Springer Nature B.V. 2021

\section{Correction to: Journal of Experimental Criminology https://doi.org/10.1007/s11292-020-09445-8}

The original version of the article unfortunately contained mistakes. In the Table 2 footnote, the number of precinct-month observations were incorrect, and the terms for the treatment effect for individual exposure months in parentheses in the second to last sentence were doubled and formatted incorrectly. The Table 2 footnote should have appeared as shown below.

Notes: Model 3 reports results for DiD models comparing shootings in months preand post-deployment of uniformed foot patrols. The 2014 panel includes 70 precincts observed over 9 months for a total of $630(n * t)$ precinct-month observations. Because the second iteration commenced 1 month earlier, the 2015 panel includes 70 precincts observed over 8 months for a total of $560(n * t)$ precinct-month observations. Column 1 is the base specification ignoring the cluster structure. Column 2 incorporates the exposure variable. Column 3 adjusts for pre-trends. Individual post-exposure effects are reported beneath the main interaction. For example, the "after" periods in 2014 represent separate estimates of the treatment effect for individual exposure months (e.g., $\hat{\delta}_{\mathrm{Jul}}$; $\hat{\delta}_{\text {Aug }} ; \hat{\delta}_{\text {Sep }}$ ). Standard errors are clustered on precinct and reported in parentheses $* p<.05 ; * * p<.01 ; * * * p<.001$ (two-tailed)

The original article has been corrected.

The original article can be found online at https://doi.org/10.1007/s11292-020-09445-8.

Sean Patrick Roche

sean.roche@txstate.edu

1 New York City Police Department, New York City, NY, USA

2 School of Criminal Justice and Criminology, Texas State University, Hines Academic Center 112, 601 University Drive, San Marcos, TX 78666, USA

3 Department of Political Science, Columbia University, New York City, NY, USA 
Publisher's note Springer Nature remains neutral with regard to jurisdictional claims in published maps and institutional affiliations. 